\title{
An unsteady extension of Bernoulli's theorem
}

\author{
by
}

Hirotada Kanehisa

Meteorological Research Institute.

Tsukuba, Ibaraki 305-0052, Japan

(submitted to the Papers in Meteorology and Geophysics, revised 25 May 1998)

\begin{abstract}
An unsteady extension of Bernoulli's theorem is presented. For steady flows, the derivative of the Bernoulli function in the normal direction perpendicular both to the streamline and the gradient of potential temperature becomes equal to the product of the flow speed and the binormal component of absolute vorticity. Even for unsteady flows, the same formula holds except that the absolute vorticity is replaced by the sum of the absolute vorticity and the local rotation rate of velocity.
\end{abstract}

\section{Introduction}

As is well known, for unforced adiabatic steady flows the Bernoulli function is conserved along the streamline. This is the classical form of Bernoulli's theorem. Recently, this theorem was generalized by Schaer (1993) and Kanehisa (1996) so that some aspects of the relationship among the Bernoulli function $B$, potential vorticity $Q$ and potential temparature $\theta$ are made clear. Schaer (1993)'s formula states that the vector product of the gradients of $\theta$ and $\mathrm{B}$ is equal to the flux of the $\mathrm{Q}^{-}$substance. Kanehisa (1996)'s formula states that with an appropriately defined stream function $\psi$ on the iso- $\theta$ surface the $\psi$-derivative of $B$ is equal to $Q$.

$\mathrm{B}, \theta$ and $\mathrm{Q}$ are properties of primary importance for meteorology. For example, the significance of $\mathrm{Q}$ is discussed in detail by Hoskins et al. (1985). For steady flows, their conservation laws along the streamlines are useful tools for analysis of atmospheric phenomena (e. g., Gutman 1991; Gutman and Apterman 1992 ; Kanehisa 1995). Absolute vorticity $f+\xi$ is also an important property, since the product of $\mathrm{Q}$ and density is the component of $\mathrm{f}+$ $\xi$ in the direction of the gradient of $\theta$.

The above mentioned steady formulae are restated as follows: The normal derivative of $\mathrm{B}$ in the

(C) 1999 by the Meteorological Research Institute direction perpendicular both to the streamline and the gradient of $\theta$ is equal to the product of the flow speed and the binormal component of $f+\xi$. In this note, it is shown that even for unsteady flows the same formula also holds except that $\mathrm{f}+\xi$ is replaced by the sum of $f+\xi$ and the local rotation rate of velocity.

The organization of this note is as follows. In section 2, fundamental equations of hydrostatic flows are presented. In section 3, Bernoulli's theorem for hydrostatic steady flows is reviewed. In section 4, the unsteady counterpart of this theorem is derived. In section 5, nonhydrostatic flows are considered. In section 6 , concluding remarks are given.

\section{Fundamental equations of hydrostatic flow}

We first consider the following hydrostatic adiabatic primitive system :

$$
\begin{aligned}
& \partial \mathrm{u}_{\mathrm{i}} / \partial \mathrm{t}+\mathrm{u}_{\mathrm{j}} \partial_{\mathrm{j}} \mathrm{u}_{\mathrm{i}}+\mathrm{w} \partial \mathrm{u}_{\mathrm{i}} / \partial z+\rho^{-1} \partial_{\mathrm{i}} \mathrm{p}-\mathrm{f} \varepsilon_{\mathrm{ij}} \mathrm{u}_{\mathrm{j}} \\
& =0 \\
& \partial \mathrm{p} / \partial z=-\mathrm{g} \rho \\
& \partial \rho / \partial \mathrm{t}+\partial_{\mathrm{i}} \rho \mathrm{u}_{\mathrm{i}}+\partial \rho \mathrm{w} / \partial z=0
\end{aligned}
$$




$$
\partial \theta / \partial \mathrm{t}+\mathrm{u}_{\mathrm{i}} \partial_{\mathrm{i}} \theta+\mathrm{w} \partial \theta / \partial z=0
$$

$\mathrm{u}_{\mathrm{i}}\left(\mathrm{u}_{1}=\mathrm{u}\right.$ and $\left.\mathrm{u}_{2}=\mathrm{v}\right)$ and $\partial_{\mathrm{i}}\left(\partial_{1}=\partial / \partial \mathrm{x}\right.$ and $\partial_{2}=\partial /$ $\partial y)$ are the horizontal velocity components and horizontal partial differential operators, respectively, with the convention of summation, $\mathrm{u}_{\mathrm{i}} \partial_{\mathrm{i}}=\sum_{\mathrm{i}=1}^{2} \mathrm{u}_{\mathrm{i}} \partial_{\mathrm{i}}$ etc.. The tensor $\varepsilon_{\mathrm{ij}}$ is defined as $\varepsilon_{\mathrm{ij}}=\delta_{\mathrm{i} 1} \delta_{\mathrm{j} 2}-\delta_{\mathrm{i} 2} \delta_{\mathrm{j} 1}$. Z and $\mathrm{w}$ are the vertical coordinate and vertical velocity, respectively. $\mathrm{t}$ is time. $\rho$ is the density, $\mathrm{p}$ the pressure and $\theta$ the potential temperature. $\mathrm{g}$ is the gravitational acceleration and $f$ the Coriolis parameter. The Coriolis parameter $\mathrm{f}$ is a function of the horizontal coordinates $\mathrm{x}_{\mathrm{i}}\left(\mathrm{x}_{1}=\mathrm{x}\right.$ and $\left.\mathrm{x}_{2}=\mathrm{y}\right)$. Under the coordinate transformation $(\mathrm{x}, \mathrm{y}, \mathrm{z}, \mathrm{t}) \rightarrow(\mathrm{x}$, $\mathrm{y}, \theta, \mathrm{t})$, Eqs. $(2-1 \mathrm{a}, \mathrm{b}, \mathrm{c})$ are transformed into

$$
\begin{aligned}
& \partial u_{i} / \partial t+u_{j} \partial_{j} u_{i}+\partial_{i} \Phi-f \varepsilon_{i j} u_{j}=0, \\
& \partial \Phi / \partial \theta=\Pi, \\
& \partial M / \partial t+u_{i} \partial_{i} M+M \partial_{i} u_{i}=0,
\end{aligned}
$$

where $\Phi=\theta \Pi+\mathrm{g} z, \Pi=\mathrm{C}\left(\mathrm{p} / \mathrm{p}_{0}\right)^{\mathrm{R} / \mathrm{c}}, \mathrm{M}=\rho \partial z / \partial \theta, \mathrm{C}$ is the specific heat at constant pressure, $\mathrm{R}$ the gas constant and $\mathrm{p}_{0}$ a reference value of $\mathrm{p}$. Hereafter $\mathrm{M}$ is assumed not to vanish. From Eqs. $(2-2 a, b, c)$, the conservation equations of the energy and potential vorticity are derived, respectively, as

$$
\begin{aligned}
& \partial E / \partial t+u_{i} \partial_{i} B=0, \\
& \text { where } E=u_{i} u_{i} / 2 \text { and } B=E+\Phi, \\
& \partial Q / \partial t+u_{i} \partial_{i} Q=0, \\
& \text { where } Q=(f+\xi) / M \text { and } \xi=\varepsilon_{i j} \partial_{i} u_{j}
\end{aligned}
$$

In Eq. (2-3a), E and B are the kinetic energy and Bernoulli function, respectively. In Eq. $(2-3 b), \xi$ and $\mathrm{Q}$ are the vorticity on the iso- $\theta$ surface and potential vorticity, respectively. After some manipulation, Eq. (2-2a) is rewritten as

$$
\partial u_{i} / \partial t+\partial_{i} B-(f+\xi) \varepsilon_{i j} u_{j}=0
$$

\section{Bernoulli's theorem for hydrostatic steady flow}

For steady flows, from Eq. $(2-2 \mathrm{c})$ there exists a stream function $\psi$ such that

$$
\mathrm{Mu}_{\mathrm{i}}=-\varepsilon_{\mathrm{ij}} \partial_{\mathrm{j}} \psi
$$

Substituting Eq. (3-1) into Eqs. (2-3a, b) gives

$$
\begin{aligned}
& \varepsilon_{\mathrm{ij}}\left(\partial_{\mathrm{i}} \psi\right) \partial_{\mathrm{j}} \mathrm{B}=0, \\
& \varepsilon_{\mathrm{ij}}\left(\partial_{\mathrm{i}} \psi\right) \partial_{\mathrm{j}} \mathrm{Q}=0 .
\end{aligned}
$$

These equations $(3-2 \mathrm{a}, \mathrm{b})$ imply that both $\mathrm{B}$ and $\mathrm{Q}$ are functions of $(\mathrm{x}, \mathrm{y})$ only through $\psi(\mathrm{x}, \mathrm{y}, \theta)$,

$$
\begin{aligned}
& \mathrm{B}=\mathrm{B}(\psi, \theta), \\
& \mathrm{Q}=\mathrm{Q}(\psi, \theta) .
\end{aligned}
$$

Substituing Eq. (3-3a) into Eq. (2-4) and using Eq. (3 -1) gives

$$
\left(\partial_{1} \psi\right) \partial \mathrm{B} / \partial \psi-(\mathrm{f}+\xi)\left(\partial_{\mathrm{i}} \psi\right) / \mathrm{M}=0 .
$$

Eq. (3-4) implies that the $\psi$-derivative of $B$ is equal to $\mathrm{Q}$ except for stagnation points,

$$
\partial \mathrm{B}(\psi, \theta) / \partial \psi=\mathrm{Q}(\psi, \theta)
$$

Eq. (3-3a) and Eq. (3-5) constitute (generalized) Bernoulli's theorem for steady hydrostatic flows. Alternatively, this theorem is expressed as

$$
\begin{aligned}
& \partial \mathrm{B} / \partial \tau=0 \\
& \partial \mathrm{B} / \partial \mathrm{n}=\mathrm{U}(\mathrm{f}+\xi),
\end{aligned}
$$

where $U=\left(u_{i} u_{i}\right)^{1 / 2}$ is the flow speed, $\partial / \partial \tau=(1 / U) u_{i}$ $\partial_{i}$ the tangential derivative along the streamline, and $\partial / \partial \mathrm{n}=-(1 / \mathrm{U}) \varepsilon_{\mathrm{ij}} \mathrm{u}_{\mathrm{i}} \partial_{\mathrm{j}}$ the normal derivative to the right of the streamline.

\section{Bernoulli's theorem for hydrostatic unsteady flow}

The velocity $u_{i}$ is expressed as a product of the speed $U$ and directional vector,

$$
\mathrm{u}_{\mathrm{i}}=\mathrm{UT}_{\mathrm{i}}(\alpha),
$$

where $\alpha=\tan ^{-1}(\mathrm{v} / \mathrm{u}), \mathrm{T}_{1}(\alpha)=\cos \alpha$ and $\mathrm{T}_{2}(\alpha)=\sin \alpha$. Since $\mathrm{dT}_{\mathrm{i}}(\alpha) / \mathrm{d} \alpha=-\varepsilon_{\mathrm{ij}} \mathrm{T}_{\mathrm{j}}(\alpha)$, the local temporal derivative of $\mathrm{T}_{\mathrm{i}}(\alpha)$ is given by

$$
\partial \mathrm{T}_{\mathrm{i}}(\alpha) / \partial \mathrm{t}=-(\partial \alpha / \partial \mathrm{t}) \varepsilon_{\mathrm{ij}} \mathrm{T}_{\mathrm{j}}(\alpha)=-\omega \varepsilon_{\mathrm{ij}} \mathrm{T}_{\mathrm{j}}(\alpha),
$$

where $\omega=\omega\left(x_{i}, t\right)$ is the local rotation rate of velocity, i. e., the local angular velocity at $\left(x_{i}, t\right)$ of the streamline passing through the point $\mathrm{x}_{\mathrm{i}}$. Substituting Eqs. (4-1) and (4-2) into Eq. (2-4) gives 


$$
\sigma \mathrm{u}_{\mathrm{i}}+\partial_{\mathrm{i}} \mathrm{B}-(\mathrm{f}+\xi+\omega) \varepsilon_{\mathrm{ij}} \mathrm{u}_{\mathrm{j}}=0,
$$

where $2 \sigma=(1 / \mathrm{E}) \partial \mathrm{E} / \partial \mathrm{t}$ is the local growth rate of kinetic energy. Multiplying Eq. (4-3) by $u_{i}$ and $\varepsilon_{i j} u_{j}$ yields respectively

$$
\begin{aligned}
& \sigma \mathrm{U}^{2}+\mathrm{u}_{\mathrm{i}} \partial_{\mathrm{i}} \mathrm{B}=0, \\
& \varepsilon_{\mathrm{ij}} \mathrm{u}_{\mathrm{j}} \partial_{\mathrm{i}} \mathrm{B}-(\mathrm{f}+\xi+\omega) \mathrm{U}^{2}=0 .
\end{aligned}
$$

Eqs. (4-4a, b) can be rewritten as

$$
\begin{aligned}
& \partial \mathrm{B} / \partial \tau=-\mathrm{U} \sigma, \\
& \partial \mathrm{B} / \partial \mathrm{n}=\mathrm{U}(\mathrm{f}+\xi+\omega) .
\end{aligned}
$$

Eqs. (4-5a, b) constitute an unsteady extension of hydrostatic Bernoulli's theorem. For steady flows both $\sigma$ and $\omega$ vanish and Eqs. (4-5a, b) are reduced to the steady counterparts Eqs. (3-6a, b). In the presence of Newtonian dissipation, Eq. (2-2a) is modified as

$$
\partial u_{i} / \partial t+u_{j} \partial_{j} u_{i}+\partial_{i} \Phi-f \varepsilon_{i j} u_{j}+\nu u_{i}=0,
$$

where $\nu$ is the dissipation coefficient, which may be a function of the spatial coordinates. In this case, Eq. (4-5b) is unaltered and Eq. (4-5a) becomes

$$
\partial \mathrm{B} / \partial \tau=-\mathrm{U}(\sigma+\nu) .
$$

\section{Case of nonhydrostatic flow}

In the case of nonhydrostatic flows, Eqs. (2-1a, b) are replaced by

$$
\partial u_{i} / \partial t+u_{j} \partial_{j} u_{i}+\rho^{-1} \partial_{i} p+\varepsilon_{i j k} f_{j} u_{k}+g_{i}=0,(5-1)
$$

where $\mathrm{i}, \mathrm{j}, \mathrm{k}$ run from 1 to 3 , and the third is the vertical component. The Coriolis parameter $f$ and gravitational acceleration $g$ are written in the vector forms as $f_{i}=\delta_{i 3} f$ and $g_{i}=\delta_{i 3} g$, respectively. The tensor $\varepsilon_{i j k}$ is defined as

$$
\begin{aligned}
\varepsilon_{\mathrm{ijk}}= & +1 \quad \text { if }(\mathrm{i}, \mathrm{j}, \mathrm{k}) \text { is an even permutation } \\
& \text { of }(1,2,3), \\
= & -1 \text { if }(\mathrm{i}, \mathrm{j}, \mathrm{k}) \text { is an odd permutation } \\
& \text { of }(1,2,3), \\
= & 0 \text { otherwise }
\end{aligned}
$$

From Eq. (5-1), the nonhydrostatic counterpart of Eq. (4-3) becomes

$$
\begin{aligned}
& \sigma \mathrm{u}_{\mathrm{i}}+\partial_{\mathrm{i}} \mathrm{B}-(\mathrm{CT} / \theta) \partial_{\mathrm{i}} \theta+\varepsilon_{\mathrm{ijk}}\left(\mathrm{f}_{\mathrm{j}}+\xi_{\mathrm{j}}+\omega_{\mathrm{j}}\right) \mathrm{u}_{\mathrm{k}} \\
& =0
\end{aligned}
$$

where $\mathrm{T}$ is the temperature, $\xi_{\mathrm{i}}$ the 3 -dimensional vorticity and $\omega_{1}$ the 3 -dimensional local rotation rate of 3-dimensional velocity. The Bernoulli function $B$ is given by

$$
\mathrm{B}=\mathrm{u}_{\mathrm{i}} \mathrm{u}_{\mathrm{i}} / 2+\mathrm{gz}+\mathrm{H},
$$

where $\mathrm{H}=\mathrm{CT}$ is the enthalpy. In Eq. (2-3a), $\mathrm{H}+\mathrm{gz}$ was expressed as $\Theta \Pi+\mathrm{gz}=\Phi$. In deriving Eq. (5-2), the following equation is used:

$$
\begin{aligned}
\partial \mathrm{u}_{\mathrm{i}} / \partial \mathrm{t} & =\partial\left(U \mathrm{Ue}_{\mathrm{i}}\right) / \partial \mathrm{t}=(\partial \mathrm{U} / \partial \mathrm{t}) \mathrm{e}_{\mathrm{i}}+U \partial \mathrm{e}_{\mathrm{i}} / \partial \mathrm{t} \\
& =(\partial \mathrm{U} / \partial \mathrm{t}) \mathrm{e}_{\mathrm{i}}+\mathrm{U} \varepsilon_{\mathrm{ijk}} \omega_{\mathrm{j}} \mathrm{e}_{\mathrm{k}} \\
& =\sigma \mathrm{u}_{\mathrm{i}}+\varepsilon_{\mathrm{ijk}} \omega_{\mathrm{j}} \mathrm{u}_{\mathrm{k}}
\end{aligned}
$$

where $e_{i}=u_{i} / U$ is the unit vector in the direction of $u_{i}$. Here is defined such a local orthonormal system that

$$
\begin{aligned}
& \tau_{\mathrm{i}}=\mathrm{e}_{\mathrm{i}}, \quad \mathrm{b}_{\mathrm{i}}=\mathrm{A}\left(\delta_{\mathrm{ij}}-\mathrm{e}_{\mathrm{i}} \mathrm{e}_{\mathrm{j}}\right) \partial_{\mathrm{j}} \theta, \\
& \mathrm{n}_{\mathrm{i}}=\mathrm{A} \varepsilon_{\mathrm{ijk}} \mathrm{e}_{\mathrm{j}} \partial_{\mathrm{k}} \theta \\
& \text { where } \mathrm{A}=\left\{\left(\partial_{\mathrm{i}} \theta\right)\left(\partial_{\mathrm{i}} \theta\right)-\left(\mathrm{e}_{\mathrm{i}} \partial_{\mathrm{i}} \theta\right)^{2}\right\}^{-1 / 2}
\end{aligned}
$$

The first unit vector $\tau_{1}$ points in the tangential direction along the streamline. The third $n_{i}$ points in the normal direction perpendicular to the plane generated by $\tau_{\mathrm{i}}$ and $\partial_{\mathrm{i}} \theta$. The second $\mathrm{b}_{\mathrm{i}}$ points in the binormal direction, which lies on the plane generated by $\tau_{\mathrm{i}}$ and $\partial_{\mathrm{i}} \theta$. Multiplying Eq. (5-2) by $\tau_{\mathrm{i}}$ and $\mathrm{n}_{\mathrm{i}}$ give respectively

$$
\begin{aligned}
& \partial \mathrm{B} / \partial \tau=-\sigma \mathrm{U}-\gamma / \mathrm{U}, \\
& \partial \mathrm{B} / \partial \mathrm{n}=\mathrm{U}(\mathrm{f}+\xi+\omega)_{\mathrm{b}},
\end{aligned}
$$

where $\gamma=(\mathrm{CT} / \theta) \partial \theta / \partial \mathrm{t}$ is the local heating rate and $(\mathrm{f}+\xi+\omega)_{\mathrm{b}}=\mathrm{b}_{\mathrm{i}}\left(\mathrm{f}_{\mathrm{i}}+\xi_{\mathrm{i}}+\omega_{\mathrm{i}}\right)$ is the binormal component of $f_{\mathrm{i}}+\xi_{\mathrm{i}}+\omega_{\mathrm{i}}$. Eqs. $(5-6 \mathrm{a}, \mathrm{b})$ constitute an unsteady extension of nonhydrostatic Bernoulli's thetrem. The nonhydrostatic Eq. (5-6b) has the same form as the hydrostatic Eq. (4-5b) except that the vertical component is replaced by the binormal. In particular for steady flows, Eqs. (5-6a, b) are reduced to

$$
\partial \mathrm{B} / \partial \tau=0,
$$




$$
\partial \mathrm{B} / \partial \mathrm{n}=\mathrm{U}(\mathrm{f}+\xi)_{\mathrm{b}}
$$

where the binormal direction coincides with the direction, of $\partial_{1} \theta$. From these equations $(5-7 a, b)$, with an appropriately defined stream function $\psi$ on the iso- $\theta$ surface (Kanehisa 1996), a formula of the same form as the hydrostatic steady Eq. (3-5) is obtained as

$$
\partial \mathrm{B}(\psi, \theta) / \partial \psi=\mathrm{Q}(\psi, \theta)
$$

where $Q=\left(f_{i}+\xi_{i}\right)\left(\partial_{i} \theta\right) / \rho$ is the nonhydrostatic potential vorticity. In the presence of dissipation of Newtonian form and diabatic heating, Eq. (5-1) and Eq. (2-1d) are modified as

$$
\begin{gathered}
\partial \mathrm{u}_{\mathrm{i}} / \partial \mathrm{t}+\mathrm{u}_{\mathrm{j}} \partial_{\mathrm{j}} \mathrm{u}_{\mathrm{i}}+\rho^{-1} \partial_{\mathrm{i}} \mathrm{p}+\varepsilon_{\mathrm{ijk}} \mathrm{f}_{\mathrm{j}} \mathrm{u}_{\mathrm{k}} \\
+\mathrm{g}_{\mathrm{i}}+\nu \mathrm{u}_{\mathrm{i}}=0 \\
\partial \theta / \partial \mathrm{t}+\mathrm{u}_{\mathrm{i}} \partial_{\mathrm{i}} \theta=\theta \mathrm{q} / \mathrm{CT}
\end{gathered}
$$

where $q$ is the material heating rate. In this case, Eq. (5-6b) is unaltered and Eq. (5-6a) becomes

$$
\partial \mathrm{B} / \partial \tau=-(\sigma+\nu) \mathrm{U}-(\gamma-\mathrm{q}) / \mathrm{U}
$$

\section{Conclusion}

In this note, an unsteady extension of Bernoulli's theorem is presented. The results are summarized in Eqs. (4-5a,b) and Eqs. (5-6a, b).

For steady flows, the derivative of the Bernoulli function $B$ in the tangential direction to the streamline vanishes. While, the derivative of $B$ in the normal direction to the right of the streamline and perpendicular to the gradient of the potential temperature $\theta$, becomes equal to the product of the flow speed $U$ and the binormal component of $3-$ dimensional absolute vorticity $\mathrm{f}+\xi$.

For unsteady flows, the tangential derivative of $\mathrm{B}$ does not vanish any longer in general. However, the normal derivative of $B$ has the same form as for steady flows except that $f+\xi$ is replaced by the sum of $f+\xi$ and the local rotation rate of velocity (i. e., of streamline).

Since $\mathrm{B}, \theta$ and $\mathrm{f}+\xi$ are of fundamental importance for meteorology, the simple formula derived in this note, which relates $\mathrm{B}, \theta$ and $\mathrm{f}+\xi$, may be a useful tool in diagosing atmospheric phenomena. It is left for our future study to apply this formula to various atmospheric phenomena.

\section{References}

Gutman, L, N., 1991 : Downslope windstorms. Part 1 : Effect of air density decrease with height. J. Atmos. Sci., 48, 2545-2551.

Gutman, L,N., and I.Apterman, 1992 : Downslope windstorms. Part 2: Effect of external wind shear. J. Atmos. Sci., 49, 1173-1180.

Hoskins, B. J., M. E. McIntyre and A. W. Robertson, 1985: On the use and significance of isentropic potential vorticity maps. Quart. J. R. Met. Soc., 111, 877-946.

Kanehisa, H., 1995 : Downslope windstorms in a uniform environmental flow with non-uniform potential temperature gradient. J. Meteor. Soc. Japan., 73, 833-837.

Kanehisa, H., 1996 : A relationship between the Bernoulli function and potential vorticity. J. Meteor. Soc. Japan., 74, 383-386.

Schaer, C., 1993 : A generalization of Bernoulli's theorem. J. Atmos. Sci., 50, 1437-1443.

\section{ベルヌウイの定理の非定常な流れへの拡張}

\section{金 久 博 忠}

\footnotetext{
ベルヌウイの定理の非定常な流れへの一つの拡張を示す。定常な流れではベルヌウイ関数の法線方向（流線と温位勾配 に垂直な方向）の微分係数は，流れの速さと絶対渦度 (の従法線方向成分) の積に等しく成る。非定常な流れに対しても， 同じ形の公式が成立する。但し, 定常な流れの絶対渦度は, 非定常な流れの場合には, 絶対渦度と（流線の）局所回転率 の和に置き替わる。
} 